\title{
Intergenerational cohesiveness and later geographic distance to parents in the Netherlands
}

\author{
Brian Joseph Gillespie ${ }^{\mathrm{a}, *}$, Tanja van der Lippe ${ }^{\mathrm{b}}$

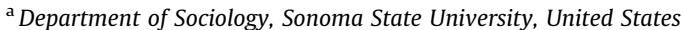 \\ ${ }^{\mathrm{b}}$ Department of Sociology/ICS, Utrecht University, The Netherlands
}

\section{A R T I C L E I N F O}

\section{Article history:}

Received 8 February 2014

Received in revised form 8 July 2014

Accepted 9 July 2014

\section{Keywords:}

Geographic proximity

Intergenerational relations

Intergenerational transfers

Kinship

Parent-child relations

\begin{abstract}
A B S T R A C T
Although spatial proximity no doubt facilitates interaction and assistance, no research to date has addressed the extent to which children who are emotionally closer to parents choose to live nearby. Using the Netherlands Kinship Panel Study $(N=1055)$, this research evaluates the relationship between parent-child cohesion at age 15 (measured retrospectively among individuals 18-35 in 2002-2004) and later geographic distance between young adults and their parents in 2006-2007. Importantly, this research is the first to consider the relationship between intergenerational solidarity and young adult's later geographic proximity to parents, proximity known to contribute to exchanges of support between the generations. For both mothers and fathers, each model yielded qualified evidence of the cohesion-proximity relationship. These findings highlight a potential selection issue related to intergenerational support and contact as it is facilitated by geographic proximity.
\end{abstract}

(c) 2014 Elsevier Ltd. All rights reserved.

\section{Introduction}

Intergenerational exchanges between adult children and their parents are a critical resource for young and old (Allen, Blieszner, \& Roberto, 2000). Residential proximity is the best predictor of these exchanges (Rossi \& Rossi, 1990; Treas \& Gubernskaya, 2012). Although spatial proximity no doubt facilitates interaction and assistance, no research to date has addressed the extent to which children who are emotionally closer to parents choose to live nearby. In other words, we do not know whether parents and grown children who live close together are those with warm and enduring relationships that predispose them to help one another.

\footnotetext{
* Corresponding author. Tel.: +1 7076643033.

E-mail addresses: bgillesp@uci.edu (B.J. Gillespie), t.vanderlippe@uu.nl (T. van der Lippe).
}

Using the Netherlands Kinship Panel Study (NKPS), this paper evaluates the relationship between parent-child cohesion at age 15 (assessed retrospectively in 20022004) for individuals aged 18-35 and later geographic distance between young adults and their parents in 20062007. Addressing the factors that draw individuals toward the parental home and those that push them away, the analysis considers the implications of a host of theoretically important variables, particularly the mediating effects of early independence on the relationship between intergenerational cohesion and residential proximity.

The present study contributes to the research on residential choice and parent-child solidarity in several ways. Importantly, this paper is the first to consider the relationship between intergenerational solidarity and young adult's geographic proximity to parents, proximity known to contribute to exchanges of support between the generations (Allen et al., 2000; Schenk \& Dykstra, 2012). By analyzing panel data on respondents spanning a wide age range, the implications of parent-child cohesion for 
proximity is studied in the context of multiple life course transitions, rather than merely nest-leaving. We examine this relationship in the Netherlands, a compact country where even "long distance" moves are relatively short, suggesting that moves will be less restricted by financial constraints and less consequential for resource exchanges.

\section{Literature review and theoretical background}

Classic theoretical formulations of migration emphasize labor migration and the equilibrating movement of workers to areas of higher wages and greater job opportunities (Cadwallader, 1992). While this is undoubtedly a driving force behind much geographic mobility, studies demonstrate that there are other motives that influence migration decisions. One is based on area characteristics and the desire to live close to amenities, such as pleasant landscapes and a favorable climate (Rappaport, 2007). Another is a preference to maintain and build on social ties (Palloni, Massey, Ceballos, Espinosa, \& Spittel, 2001), an idea sometimes framed as "location-specific capital," influencing decisions of where to relocate (DaVanzo, 1981). While acknowledging the importance of labor market considerations as a predictor of migration, this paper aims to understand to what extent migration also depends on intergenerational dynamics and subjective preference.

Following prior theorizing about migration (Longley, Clarke, \& Williams 1991; Sjaastad, 1962), in deciding where to live, it is assumed that individuals seek to maximize economic (e.g., income) and noneconomic (e.g., life satisfaction) gains and to minimize costs within a structure of opportunities (e.g., jobs), constraints (e.g., housing), and cultural norms and personal preferences (e.g., familistic values). When young adults make a residential choice, distance to parents is one consideration they weigh. Importantly, the costs and gains associated with living nearby or far away will depend, in part, on the quality of the parent-child relationship. Although residential distance between parents and children is a "two actor problem," we start with the assumption that the choice is largely the child's, because young adults are much more mobile than older ones (Geist \& McManus, 2008; Long, 1992).

Bengtson and Roberts (1991) distinguished six dimensions of family solidarity, including affective (psychological closeness), associational (contact), and structural (proximity). Spatial proximity to parents is highly predictive of contact (Rossi \& Rossi, 1990), which is itself important for the intergenerational exchange of vital services and support (Bengtson \& Roberts, 1991). Researchers recognize that the positive correlation of proximity and contact may be due, in part, to the fact that children who feel closer emotionally to parents choose to live closer to parents. Further, although there is some evidence that parent-child relationships influence the child's departure from the parental home (Ward \& Spitze, 2007), this hypothesis for proximity has not yet been tested.

Intergenerational geographic proximity plays a crucial role in determining the intensity and frequency of contact between parents and children (Bian, Logan, \& Bian, 1998; Rossi \& Rossi, 1990). The distance an individual lives from parents determines contact and support and therefore has important implications for long-term care of aging parents, despite the development of cell phones and other communication technologies (Treas \& Gubernskaya, 2012). Several studies have recently detailed the factors contributing to the spatial separation of adult children and their parents (e.g., Michielin \& Mulder, 2007). Nevertheless, these studies have almost exclusively focused on individual characteristics, such as children's educational attainment (Kalmijn, 2006); parental characteristics, such as age, marital status, and health (DeWit, Wister, \& Burch, 1988); and household size and family composition (Klein Ikkink, van Tilburg, \& Knipscheer, 1999). Drawing on the life course perspective (Elder, 1998), this study aims to expand the focus from the individual and household to include the broader family context.

\subsection{The life course perspective}

This study benefits from each of Elder's (1987, 1994, 1998) four critical concepts of the life course perspective. "Linked lives" proposes that individual lives are lived interdependently and "typically embedded in social relationships with kin and friends across the life span" (Elder, 1994, p. 6). This concept inspires the research question about the consequences of parent-child cohesion that motivates the research. "Timing in lives" refers to the notion that certain life events will affect individuals differently depending on when they occur in their life. This concept motivates the hypothesis regarding young adults' age at departure from the parental home.

Elder's (1987, 1994, 1998) concept of "human agency" refers to individuals' ability to navigate their lives within the constraints of their social circumstances. In other words, individuals are active agents in shaping their lives based on individual values and preferences but only within their reasoned ability. Thus, individuals may choose to move far from their parents, although their actions may be constrained if they have limited ability to do so. Last, drawing from Elder's "historical time and place," crossnational implications of this research are discussed.

\subsection{Kin networks, intergenerational solidarity, and "linked} lives"

“Linked lives" proposes that individuals' lived experiences are situated within, and expressed through, networks of shared relationships (Elder, 1998). Massey's (1990) review of the migration literature highlights how networks link individual and household decisions to macrosocial structures. In an economic and social context, Massey suggests that individuals are linked to one another through kinship and social networks rather than acting as singular rational beings. He shows that individuals, families, and communities are important elements of social structure that contribute to migration. These associations are important for migration for two reasons: (a) residential mobility is safer and more predictable because of information passed along social networks to 
other potentially mobile individuals and (b) kinship networks allow for the flow of capital (e.g., sending remittances home) which spurs subsequent migration.

Although families can promote migration, individuals may also remain in an area because of social and kin network ties (Spilimbergo \& Ubeda, 2004). Early research supports the idea that family ties can deter residential mobility (Mincer, 1978). Sandefur and Scott (1981) posit important reasons for larger households being less inclined to move, namely, that additional social ties are broken with the move of each individual family member. This undesirable loss of social capital may be even worse when families relocate repeatedly (Coleman, 1988). For young adults, moving away from supportive parents can similarly result in a loss of the benefits of the relationship.

Taken as a whole, these results suggest that individual and family-based factors affect the choice to residentially relocate and where. Not considered is the affective cohesion between parent and child as a motivator of residential proximity. To date, no research has examined whether and how intergenerational solidarity is associated with parent-adult child proximity, especially emotional closeness and spatial distance as a product of time and space.

\subsubsection{Intergenerational cohesion}

Of Bengtson and Roberts' (1991) six dimensions of family solidarity, sociologists and demographers have been most interested in structural solidarity (based on coresidence, proximity, and kin availability). At the same time, the relationship between affective solidarity and the distance component of structural solidarity is not well understood. We do know that there is variation in the emotional closeness of kin (Pyke, 1999) and that relationships can constitute both positive social supports and negative influences (Kalmijn \& Graaf, 2012; Sorkin \& Rook, 2006). Residential location may provide a rational strategy to retain positive benefits of a good relationship and avoid the downside of a poor one.

Parents and children differ in their degree of affectual cohesion. Factors, such as household conflict, size, and structure, contribute to emotional detachment (Conger, Ge, Elder, Lorenz, \& Simons, 1994; Hair, Moore, Garrett, Ling, \& Cleveland, 2008). Early intergenerational cohesion has been shown to have long-run consequences for various aspects of parent-child relations (Farrell \& Barnes, 1993; Kalmijn, 2006; Merz \& Jak, 2013; Rossi \& Rossi, 1990). Demographic shifts, such as longer life expectancy, changing household size and structure, and geographic dispersion have created an increased need to study relations between the dimensions of contemporary intergenerational solidarity (Steinbach, 2012; Swartz, 2009).

Children who are emotionally close to their parents receive more financial and emotional support from them later in life (Silverstein, Conroy, Wang, Giarrusso, \& Bengtson, 2002). Of course, contact and support is facilitated if these children choose to live closer to their parents. Thus, the relationship between affectual solidarity and contact may reflect selection of emotionally close dyads into spatially close pairs.

\subsection{Departure from the parental home and "timing in lives"}

"Timing in lives" is concerned with how certain life events affect individuals differently depending on when they occur in a person's life. In support of this notion, researchers have found that the timing of a young adult's departure from the parental household affects later spatial distance from parents (Michielin \& Mulder, 2007). This is generally thought to be because moving away from the parental home at an early age affords an individual more time for subsequent long-distance moves (Rogerson, Weng, \& Lin, 1993). In other words, these subsequent moves are made independent from the parental home, and therefore, will increase residential distance. Since children who are not close to their parents are more prone to moving at earlier ages (Ward \& Spitze, 2007), we anticipate that the relationship between cohesion and later spatial distance will be mediated by early independence from the parental home.

\subsection{Correlates of parent-child geographic distance (human agency)}

The concept of "human agency" refers to individuals' ability to navigate their lives within the constraints of their social circumstances. However, social structures do not only constrain human agency, they also enable it. Therefore, in determining factors affecting the geographic distance between parents and their adult children, one must take into account the various needs and constraints that would limit an individual from distance migration and the preferences as well as the opportunities that "push" people to move far.

\subsection{1. "Pull" factors: needs, obligations, and constraints}

The decision to remain close to parents is often based on financial need, feelings of personal responsibility, and familism. Despite a desire to move far, one's ability to do so may be constrained if an individual has limited means. In this case, support from parents may also be facilitated by remaining close to their parents (Cheal, 1983). In support of this, Greenwell and Bengtson (1997) found that parents' social class is negatively associated with spatial distance from their adult children.

Caretaking responsibilities for aging parents, especially parents who are in ill health, could also influence the decision to remain close to the parental home (Michielin \& Mulder, 2007; Mulder \& Kalmijn, 2006). Klein Ikkink et al. (1999) found that only children live closer to their mothers perhaps because there are no other siblings to provide care to aging parents. Regardless of parental health and age, familism may promote an individual's decision to remain close to parents and extended family. For example, Lin and Rogerson (1995) found that individuals with children live closer to their parents than childfree individuals, perhaps because of the important part that grandparents play in their grandchildren's lives.

\subsection{2. "Push" factors: opportunities, resources, and preferences}

As noted, individuals with larger familial networks might be less inclined to move far because of their family 
ties. On the other hand, adult children with large families might also be better equipped to move because siblings can care for aging parents. Thus, the presence, number, age, gender, and location of siblings might relieve an individual of caretaking responsibilities of aging parents (IngersollDayton, Neal, Ha, \& Hammer, 2003; Klein Ikkink et al., 1999; Michielin \& Mulder, 2007; Rainer \& Siedler, 2012). In support of this, Klein Ikkink et al. (1999) found that older siblings move farther than younger siblings. These researchers, along with Konrad, Kunemund, Lommerud, and Robledo (2002), hypothesized that older children move farther away from their parents to avoid the burden of elder care.

As females are often kinkeepers (Rosenthal, 1985) and caretakers (Sarkisian \& Gerstel, 2004) within the family, individuals with sisters are more likely to live far from their parents than individuals without sisters (IngersollDayton et al., 2003). Sibling proximity to parents is another important factor influencing an individual's distance to their parents; individuals with siblings who live close to their parents are more likely to live far (Michielin \& Mulder, 2007). Additional kinship ties for the parent outside of the household, such as their own siblings, play an instrumental part in financial and social support (Knijn \& Liefbroer, 2006) and may relieve an individual's caretaking responsibilities and contribute to their ability and decision to move far from the parental home.

Geographic opportunity structure (e.g., one's educational and employment prospects) is another main factor in the decision and ability to move away from one's parents. Lee, Dwyer, and Coward (1990) and Lin and Rogerson (1995) found that children in less urbanized areas live farther from their parents, and Mulder and Kalmijn (2006) hypothesize that this is because individuals from denser areas have less need to move far for education or work reasons. Also, reflecting the labor market for their services, college educated individuals live farther away from the parental home than individuals with a high school diploma or less (Rogerson et al., 1993). In fact, most research finds that with the exception of education, no attribute of child or mother consistently affects distance from parents.

\subsection{Historical time and place}

Elder's concept of historical time and place is concerned with how individuals' experiences are shaped by the historical and spatial contexts in which they are embedded. The Netherlands is characterized by a number of factors which may be of importance for the relationship between emotional closeness and spatial distance. Socialized to early independence (Ciairano, Kliewer, Bonino, \& Bosma, 2008), young Dutch people leave home at a relatively young age compared to many other European countries (Iacovou, 2010; Leopold, 2012).

Because dependent care responsibility in the Netherlands lies more with the state than the United States and the UK, the need for parent-child proximity to facilitate family care may be less prominent. Furthermore, individuals in the Netherlands view childcare as the parents' responsibility as opposed to the responsibility of the state and the family at large (Liefbroer \& Mulder, 2006), although recently, the role of grandparents has increased in this respect (Glaser, Price, Montserrat, di Gessa, \& Tinker, 2013).

The Netherlands has many more part-time workers as well as relatively short maximum work hours mandated by law (van der Lippe \& van Dijk, 2002). Although this implies more opportunities for intergenerational contact, it also suggests that proximity may be less consequential to parent-child interaction and exchange than, for example, in the U.S. where leisure time is more limited. Also helping to overcome impediments of geographic distance, public transportation is better developed in the Netherlands than the United States and other Western countries.

\section{Hypotheses}

It is not well understood whether family factors influence spatial proximity outcomes for young adults, because most studies on intergenerational spatial proximity are cross-sectional and focus only on adolescents or the elderly. Further, the implications of early family characteristics for young adult spatial outcomes have not been widely explored. We expect that young adults who did not have emotionally close relationships with their mother or father will live farther from them later in life. In this case, a young adult will have greater motivation to seek out new surroundings and a decreased desire to rely on parents for emotional and other rewards. Instead, these motivations are apt to be expressed in social and environmental choices consistent with skill acquisition and expanding one's horizons (e.g., educational and occupational attainment). Furthermore, reflecting the quality of the parent-child relationship, the timing of the child's initial departure from the parental home might mediate the relationship between parent-child solidarity and later residential proximity.

Summarizing, the following three hypotheses will be tested in this paper:

(1) early intergenerational cohesion will be negatively associated with later young adult spatial distance to parents,

(2) early nest-leaving will be positively associated with adult spatial distance to parents,

(3) early intergenerational cohesion will have a negative effect on spatial distance, and this effect will be mediated by early independence from the parental home.

\section{Data and method}

\subsection{The Netherlands Kinship Panel Study}

This study is based on data from the Netherlands Kinship Panel Study (Dykstra et al., 2005). The NKPS is a nationally representative survey of individuals living in the Netherlands. Importantly for the present research, the primary focus of the survey is to measure solidarity among family members. Data have been collected on several 
different dimensions of family solidarity, including the affective (psychological closeness), associational (contact), and structural (proximity) cohesion among respondents and their kinship networks.

The NKPS contains extensive information on family processes based on the report of an "anchor" respondent. It has collected an array of information about parent-child relationships, residential location of family members, and other environmental characteristics. The survey also collects extensive information on parents of the anchor respondents. Data collection was undertaken with structured and in-depth interviews between 2002 and 2004 for the first wave (T1) $(N=8161$; Ages 18-79). The second wave of data (T2) was collected between September 2006 and June 2007 with about $74 \%$ of households from the original survey participating. Data are reweighted to correct for attrition. The primary focus of the second wave of the NKPS was to measure changes that occurred among respondents and their families following the first wave.

As the most mobile phase of the life course (Long, 1992; U.S. Census, 2012), and following convention (Mulder, Clark, \& Wagner, 2002), this study uses the data collected from respondents between ages 18 and 35 in the first wave of the NKPS. Missing responses were imputed on the independent variables (15.6\% for mothers and $18.6 \%$ for fathers). Because of this moderate amount of missing data in the sample, a chained multiple imputation procedure was utilized to handle missing data (Allison, 2002). Dependent and independent variables were used to construct the imputations but imputed values for dependent variables were dropped before conducting analyses. Bodner (2008) recommends having as many imputations as the percentage of missing data. As such, the imputation procedure produced 20 imputed datasets and the imputed estimates were subsequently combined. Descriptive statistics and parameter estimates for each imputed dataset were virtually identical. This yielded a final analytic sample of 1055 . Table 1 presents the descriptive statistics for the restricted sample population.

\subsubsection{Dependent variable (spatial proximity at NKPS Wave 2)}

Distance to parents is the logged kilometric distance between the residences of the respondent and parent based on postal codes provided at Wave 2. The log transformation was performed to avoid heteroskedasticity (Kalmijn, 2006). Taking the logarithm of the variable also facilitates intuitive interpretation because a single unit kilometric difference is expected to be less consequential at increasing istances (Silverstein, 1995).

\subsubsection{Key independent variables}

Early Intergenerational cohesion was measured in the first NKPS wave by the respondent's report of how emotionally close he/she felt to each parent at age 15 . The early parent-child relationship was gauged using a summed scale based on four Likert-type measures: "I could always turn to my mother/father if I had problems," "My mother/father and I were very close," "I always felt that my mother/father supported me," and "My mother/father understood very well what was on my mind." The possible responses were strongly disagree (1); disagree (2); neither agree nor disagree (3); agree (4); strongly agree (5). If one of the parents was not living when the respondent was 15 years old, this question refers to the situation immediately preceding the parent's death. The summed scale ranged from 4 to 20 (with higher numbers indicating a closer parent-child relationship) and $\alpha=.87$ for mothers and .83 for fathers.

Following Michielin and Mulder (2007), an "early independence" variable was constructed for whether or not the respondent left the parental home at an early age, that is, within the first age quartile of leaving the parental home (i.e., prior to age 19; achieved early independence $=1$, else $=0$ ).

\subsubsection{Other variables}

Parental relationship: To measure ways in which the parental household may be inhospitable, relationship quality of the mother and father at age 15 (measured at Wave 1 in 2002-2004) is included in the analysis. Five questions probed how often the respondent's parents had heated discussions, put down and blamed each other, did not want to talk to each other for a while, had arguments that got out of hand, and had lived apart for a while when the respondent was about 15 years old. If one of the parents was not living or if the parents divorced before the respondent was 15 years old, this question refers to the situation immediately preceding the death or divorce. Response categories were never (1), once or twice (2), or frequently (3). The summated scale ranges from 1 to 15 (with higher numbers indicating more conflict between parents) and $\alpha=.75$.

In order to control for the parent-child relationship at Time 2, the respondent reported on whether he or she "had any conflicts, strains or disagreements with father/mother during the past three months." The possible responses are: not at all (1), once or twice (2), and several times (3).

Needs and constraints ("pull" factors): Constraints to distance mobility include the young adult's status as an only child $(=1$, else $=0)$ and an interval level variable for the respondent's number of children at $\mathrm{T} 2$. To gauge the parent's capacity for independent living and the need for kin help, the respondent's report of their parent's health is coded as very bad (1), bad (2), not good and not bad (3), good (4), and excellent (5). A dummy variable, disabled, indicates whether the child reported the parent as being seriously ill or disabled. Urban residence at age 15 is a five-point scale with a score of " 1 " indicating highly rural and " 5 " indicating highly urban.

Opportunities and preferences ("push factors"): Highest grade of schooling completed is an ordinal measure coded as: incomplete elementary (1), elementary school (2), lower vocational (3), lower general intermediate (4), upper general intermediate (5), pre-university (6), short intermediate vocational (7), intermediate vocational (8), higher vocational (9), university (10), and post-graduate (11). Current or most recent International Socioeconomic Index score (ISEI) for occupational status was resized (divided by 10 ) to present larger parameter estimates (Ganzeboom, De Graaf, \& Treiman, 1992; Michielin \& Mulder, 2007).

Marital status at T2 is a dummy variable indicating whether the respondent is married or cohabitating with a 
Table 1

Descriptive statistics.

\begin{tabular}{|c|c|c|c|}
\hline Variables & Mean (SD) & $N$ & $n(\%)$ \\
\hline \multicolumn{4}{|l|}{ Dependent variables } \\
\hline Distance to Mother $(\mathrm{km})_{2}$ & $29.8(43.6)$ & 1055 & \\
\hline Distance to Father $(\mathrm{km})_{2}$ & $30.9(44.1)$ & 1055 & \\
\hline \multicolumn{4}{|l|}{ Intergenerational cohesion } \\
\hline Closeness to Mother $_{\text {Age } 15}$ & $14.6(3.9)$ & 1004 & \\
\hline Closeness to Father $_{\text {Age } 15}$ & $13.4(3.8)$ & 1004 & \\
\hline Mother-Child Conflict 2 & $1.2(.49)$ & 1035 & \\
\hline Father-Child Conflict ${ }_{2}$ & $1.2(.43)$ & 996 & \\
\hline Mother-Father Relationship ${ }_{\text {Age } 15}$ & $7.1(2.0)$ & 1042 & \\
\hline Early Independence & & 1055 & $251(23.8)$ \\
\hline \multicolumn{4}{|l|}{ Needs and constraints } \\
\hline Mother Health ${ }_{2}$ & $3.8(.70)$ & 1042 & \\
\hline Father Health ${ }_{2}$ & $3.7(.77)$ & 1015 & \\
\hline Urbanization $_{\text {Age } 15}$ & $2.6(1.3)$ & 1055 & \\
\hline Number of Children $_{2}$ & $1.2(1.2)$ & 1055 & \\
\hline Mother Disability 2 & & 1035 & $120(11.6)$ \\
\hline Father Disability $_{2}$ & & 966 & $144(14.5)$ \\
\hline Only Child & & 1055 & $48(4.55)$ \\
\hline \multicolumn{4}{|l|}{ Opportunities and preferences } \\
\hline Socioeconomic Status ${ }_{1}$ & $5.1(1.6)$ & 1026 & \\
\hline Education $_{2}$ & $7.8(2.2)$ & 1055 & \\
\hline Brothers $_{1}$ & $1.0(.98)$ & 1055 & \\
\hline Sisters $_{1}$ & $1.0(1.0)$ & 1055 & \\
\hline Mother Siblings $_{1}$ & $3.9(2.8)$ & 1052 & \\
\hline Father Siblings ${ }_{1}$ & $3.7(2.6)$ & 1047 & \\
\hline Employed/enrolled $_{2}$ & & 1055 & $939(89.0)$ \\
\hline Married $_{2}$ & & 1055 & $586(55.6)$ \\
\hline Oldest Child $_{1}$ & & 1055 & $385(36.5)$ \\
\hline \multicolumn{4}{|l|}{ Sibling proximity to mother/father ${ }_{1}$} \\
\hline Only Child (Reference) & & 1018 & $48(4.7)$ \\
\hline$\geq 1$ Sibling within $10 \mathrm{~km}$ of Mother & & 1018 & $686(72.1)$ \\
\hline All Siblings $>10 \mathrm{~km}$ of Mother & & 1018 & $284(27.9)$ \\
\hline$\geq 1$ Sibling within $10 \mathrm{~km}$ of Father & & 1016 & $681(67.0)$ \\
\hline All Siblings $>10 \mathrm{~km}$ of Father & & 1016 & $287(28.3)$ \\
\hline \multicolumn{4}{|l|}{ Proximity to in-laws 2} \\
\hline No In-Laws (Reference) & & 1007 & $275(27.3)$ \\
\hline Live with/within $10 \mathrm{~km}$ of $\geq 1$ In-Law & & 1007 & $438(43.5)$ \\
\hline$>10 \mathrm{~km}$ from in-laws & & 1007 & $294(29.2)$ \\
\hline \multicolumn{4}{|l|}{ Controls } \\
\hline Female & & 1055 & $679(64.4)$ \\
\hline Age $_{1}$ & $29.5(4.0)$ & 1055 & \\
\hline Mother Education $_{1}$ & $4.6(2.1)$ & 1025 & \\
\hline Father Education $_{1}$ & $5.3(2.5)$ & 1007 & \\
\hline
\end{tabular}

partner (1) or not (0). Separate interval-level measurements mark the number of living brothers and sisters who were reported at $\mathrm{T} 1$. A dichotomous variable indicates whether the respondent is the oldest child $(=1$, else $=0)$. The respondent's report of their parents' number of living siblings at $\mathrm{T} 2$ is also included.

To measure kin availability outside of the household, a series of dummy variables indicates whether or not a respondent has no in-laws (reference category); lives with at least one parent-in-law; lives within $10 \mathrm{~km}$ of at least one parent-in-law; and lives farther than $10 \mathrm{~km}$ from both parents-in-law. A series of dummy variables also indicates whether or not the respondent has no siblings (reference category); at least one sibling lives within $10 \mathrm{~km}$ of parent; all siblings live farther than $10 \mathrm{~km}$ from parent. These measures are based on zip codes provided by the anchor respondent.
Control variables. Additional control variables include the respondent's age, gender (female $=1$, male $=0$ ), and parental education. A single dummy variable indicates whether or not the respondent is enrolled in school or employed fulltime $(=1$, unemployed/non-student $=0)$. We acknowledge that a more robust test of Hypothesis 1 would include an additional control for parent-child spatial proximity at Wave 1 . However, given that many respondents did not relocate between Waves 1 and 2, there was not enough statistical power for its inclusion in the final regression models.

\subsection{Analytic strategy}

Given that both dependent variables (spatial distance to mother and father) and the main independent variable (early emotional closeness to mother/father) describe 
overlapping characteristics of each parent, seemingly unrelated regression (SUR) was adopted for the analytic models. SUR analyses model the individuals' logged distance to each parent at T2 against their reported closeness at age 15 (measured at T1). This approach is advantageous for family research where it is unlikely that the dependent variables are mathematically independent (Godwin, 1985; Kalmijn \& Bernasco, 2001). SUR accounts for this and the correlation in error terms and, thus, makes ordinary least squares regression an inappropriate test at worst and an inefficient one at best (Godwin, 1985). The use of SUR is supported by results of the Breusch-Pagan test for conditional heteroscedasticity $\left(X^{2}=897.6\right.$, $p<.001$ ) which indicates that the residuals are very highly correlated.

The individual analyses for mothers and fathers proceed in four steps. First, there is a baseline model showing the bivariate relationship between parent-child cohesion at age 15 and $\mathrm{T} 2$ proximity. The second model adds a series of controls to determine whether early closeness remains a unique contributor to later distance when confounding influences are taken into account. Third, early independence is added in order to see its relative contribution to spatial distance.

\section{Results}

At Wave 1, anchor respondents reported an average emotional closeness of 14.6 $(\mathrm{SD}=3.9)$ to mothers at age 15 . For emotional closeness to fathers at age 15, respondents averaged $13.4(\mathrm{SD}=3.8)$. At Wave 2 , respondents averaged $29.8 \mathrm{~km}$ from their mother $(\mathrm{SD}=43.6)$ and $30.9 \mathrm{~km}$ from their father $(S D=43.95)$. Preliminary results suggest that individuals who reported less-than-average closeness to their mother at age 15 live farther from her at Wave 2 $(t=3.3 ; d f=3444 ; p<.001)$. Individuals at Wave 1 who reported a less-than-average level of closeness to their father at age 15 live farther from him at Wave $2(t=3.1$; $d f=2475 ; p<.001)$.

\subsection{Distance to mother}

Table 2 presents the results of the seemingly unrelated regression of early intergenerational cohesion on later spatial distance to mother. Baseline results for closeness to mother at time 1 and spatial distance to mother at time 2 reveal that without controls, emotional closeness at age 15 is significantly associated with less residential distance to mother $(\beta=-.01, p<.05)$.

Model 2 tests the cohesion model with adjustment for a large set of control variables that include additional measures of family solidarity, push, and pull factors. Net of controls, the effect of mother-child closeness at age 15 is still negative and significant, indicating that individuals who reported being emotionally close to their mothers live closer to their mothers later $(\beta=-.02, p<.01)$. The control variables for age, gender, mother's education, and employment status or school enrollment do not significantly predict distance to mother.

Living farther than $10 \mathrm{~km}$ from in-laws is associated with living farther from mother than is the case if there are
Table 2

Seemingly unrelated regression examining predictors of distance to mother (T2) $N=1055$.

\begin{tabular}{|c|c|c|c|}
\hline & $\begin{array}{l}\text { Model } 1 \\
\beta\end{array}$ & $\begin{array}{l}\text { Model } 2 \\
\beta\end{array}$ & $\begin{array}{l}\text { Model } 3 \\
\beta\end{array}$ \\
\hline \multicolumn{4}{|l|}{ Intergenerational cohesion } \\
\hline 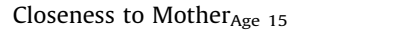 & $-0.01^{*}$ & $-0.02^{*}$ & $-0.02^{* *}$ \\
\hline Early Independence & & & $0.71^{* * *}$ \\
\hline Mother-Child Conflict 2 & & -0.08 & -0.08 \\
\hline Mother-Father & & 0.04 & 0.03 \\
\hline \multicolumn{4}{|l|}{ Relationship $_{\text {Age } 15}$} \\
\hline \multicolumn{4}{|l|}{ Needs and constraints } \\
\hline Only Child & & -0.30 & -0.22 \\
\hline Mother Health 2 & & -0.01 & -0.01 \\
\hline Mother Disability $_{2}$ & & $-0.13^{*}$ & $-0.13^{*}$ \\
\hline Urbanization $_{\text {Age } 15}$ & & $-0.14^{* * *}$ & $-0.14^{* * *}$ \\
\hline Number of Children $_{2}$ & & $-0.20^{* * *}$ & $-0.20^{* * *}$ \\
\hline \multicolumn{4}{|l|}{ Opportunities and preferences } \\
\hline Socioeconomic Status 2 & & $0.20^{* * *}$ & $0.20^{* * *}$ \\
\hline Education $_{2}$ & & $0.12^{* * *}$ & $0.11^{* * *}$ \\
\hline Married $_{2}$ & & -0.07 & -0.19 \\
\hline Brothers $_{1}$ & & 0.04 & 0.05 \\
\hline Sisters $_{1}$ & & $0.21^{* * *}$ & $0.19^{* * *}$ \\
\hline Oldest Child $_{1}$ & & 0.13 & 0.14 \\
\hline Mother Siblings $_{1}$ & & 0.01 & 0.01 \\
\hline \multicolumn{4}{|l|}{ Kin availability } \\
\hline \multirow{2}{*}{\multicolumn{4}{|c|}{$\begin{array}{l}\text { Sibling Proximity to Parents }{ }_{1} \\
\text { No Siblings (Reference) }\end{array}$}} \\
\hline & & & No Siblings (Reference) \\
\hline $\begin{array}{l}\geq 1 \text { Sibling within } 10 \\
\text { km of Mother }\end{array}$ & & -0.30 & -0.28 \\
\hline All Siblings Live $>10 \mathrm{~km}$ of Mother & & 0.36 & 0.33 \\
\hline \multicolumn{4}{|l|}{ Proximity to In-Laws 2} \\
\hline \multicolumn{4}{|l|}{ No In-Laws (Reference) } \\
\hline $\begin{array}{l}\text { Live with/within } 10 \mathrm{~km} \\
\text { of } \geq 1 \text { In-Law }\end{array}$ & & -0.19 & -0.02 \\
\hline$>10 \mathrm{~km}$ from In-Laws & & $0.73^{* *}$ & $0.81^{* *}$ \\
\hline \multicolumn{4}{|l|}{ Controls } \\
\hline Age $_{1}$ & & -0.01 & -0.00 \\
\hline Female & & 0.04 & 0.04 \\
\hline Employed/Enrolled $_{2}$ & & 0.14 & 0.14 \\
\hline Mother Education $_{1}$ & & 0.02 & 0.02 \\
\hline Constant & $2.29^{* * * *}$ & 0.78 & 0.62 \\
\hline Average adjusted $R^{2}$ & 0.01 & 0.23 & 0.25 \\
\hline
\end{tabular}

no in-laws $(\beta=.73, p<.01)$. As expected, socioeconomic status and education, indicative of resources and opportunities to move far, are positive and significant. Thus, individuals with higher SES $(\beta=.20, p<.001)$ and greater education $(\beta=.12, p<.001)$ live farther from their mother at time 2 . Number of sisters $(\beta=.21, p<.001)$ is also significantly and positively associated with T2 distance from mother. On the other hand, living in an urbanized area at age $15(\beta=-.14, p<.01)$, number of respondent's children $(\beta=-.20, p<.01)$ and mother's disability status $(\beta=-.13, p<.05)$ are associated with living closer to mother.

Model 3 includes the net effect of early independence from the parental household. Similar to Model 2, T1 emotional closeness to mother remains significant and 
negative $(\beta=-.02, p<.01)$. Early independence from the parental household is strongly associated with living farther from mother $(\beta=.71, p<.001)$. Thus, early independence is an independently significant predictor of T2 spatial proximity to mother. The significant relationship between parent-child cohesion is not mediated by early independence. At the same time, all Model 1 control relationships remain significant in this model.

These results imply that early emotional closeness to mother and early independence from the parental household are independently significant predictors of T2 distance to mother. The relationship between early emotional closeness to mother and later spatial distance is not mediated by early independence.

\subsection{Distance to father}

Turning to fathers, the bivariate relationship in Model 1, Table 3, presents the baseline results for T1 closeness to father and $\mathrm{T} 2$ spatial distance to father. These results reveal that, without controls, emotional closeness is significantly associated with greater distance to father $(\beta=-.01$, $p<.05)$. Similar to the models for mother, Model 2 adds a series of control variables to examine the significance of the relationship between cohesion and proximity net of other factors.

In Model 2, the effect of father-child closeness at age 15 (reported at Wave 1) is still negative and significant, which suggests that individuals who are emotionally close to their fathers live closer to them later $(\beta=-.02, p<.05)$. Again, the control variables for age, gender, father's education, and employment/enrollment are non-significant predictors of T2 spatial distance to father.

Individuals who live more than $10 \mathrm{~km}$ from their inlaws (compared to not having in-laws) live farther from their father $(\beta=.34, p<.05)$. Similar to mothers, urbanization at age $15(\beta=-.14, p<.001)$, and number of children $(\beta=-.19, p<.001)$ are also associated with living closer to father. Socioeconomic status $(\beta=.18$, $p<.05)$, education $(\beta=.13, p<.05)$, and number of sisters $(\beta=.21, p<.001)$ are all positively associated with greater T2 distance from father. However, unlike mothers, father's disability status is not a significant predictor of T2 distance.

Model 3 includes an additional measure, early independence, to examine its relationship to T2 residential distance to fathers. As expected, early independence is significantly associated with living farther $(\beta=.65$, $p<.001)$. Cohesion is independently and negatively associated with proximity to father. That is, individuals who report having had a close relationship with their fathers at age 15 live closer to them later $(\beta=-.01$, $p<05$ ). Similar to mothers, early independence is an independently significant predictor of T2 spatial proximity to father. The significant relationship between fatherchild cohesion is not mediated by early independence. Sibling proximity to father and respondent's proximity to in-laws are no longer significant in this model. All other significant relationships from Model 2 are maintained in this model.
Table 3

Seemingly unrelated regression examining predictors of distance to father $(N=1055)$.

\begin{tabular}{|c|c|c|c|}
\hline & $\begin{array}{l}\text { Model } 1 \\
\beta\end{array}$ & $\begin{array}{l}\text { Model } 2 \\
\beta\end{array}$ & $\begin{array}{l}\text { Model } 3 \\
\beta\end{array}$ \\
\hline \multicolumn{4}{|l|}{ Intergenerational cohesion } \\
\hline Closeness to Father $_{\text {Age } 15}$ & $-0.01^{*}$ & $-0.02^{*}$ & $-0.01^{*}$ \\
\hline Early Independence & & & $0.65^{* * * *}$ \\
\hline Father-Child Conflict 2 & & 0.01 & 0.01 \\
\hline Mother-Father & & 0.05 & 0.04 \\
\hline \multicolumn{4}{|l|}{ Relationship $_{\text {Age } 15}$} \\
\hline \multicolumn{4}{|l|}{ Needs and constraints } \\
\hline Only Child & & -0.10 & -0.03 \\
\hline Father Health 2 & & 0.02 & 0.01 \\
\hline Father Disability $_{2}$ & & 0.07 & 0.07 \\
\hline Urbanization $_{\text {Age } 15}$ & & $-0.14^{* * *}$ & $-0.14^{* * *}$ \\
\hline Number of Children $_{2}$ & & $-0.19^{* * *}$ & $-0.19^{* * *}$ \\
\hline \multicolumn{4}{|c|}{ Opportunities and preferences } \\
\hline Socioeconomic Status $_{2}$ & & $0.18^{* * * *}$ & $0.17^{* * *}$ \\
\hline Education $_{2}$ & & $0.13^{* * *}$ & $0.12^{* * * *}$ \\
\hline Married $_{2}$ & & 0.25 & 0.15 \\
\hline Brothers $_{1}$ & & 0.05 & 0.05 \\
\hline Sisters $_{1}$ & & $0.21^{* * *}$ & $0.19^{* * * *}$ \\
\hline Oldest Child $_{1}$ & & 0.12 & 0.13 \\
\hline Father Siblings $s_{1}$ & & -0.00 & 0.00 \\
\hline \multicolumn{4}{|l|}{ Kin availability } \\
\hline \multicolumn{4}{|l|}{ Sibling Proximity to Parents ${ }_{1}$} \\
\hline \multicolumn{4}{|l|}{ No Siblings (Reference) } \\
\hline $\begin{array}{l}\geq 1 \text { Sibling within } 10 \mathrm{~km} \\
\text { of Father }\end{array}$ & & -0.09 & -0.08 \\
\hline $\begin{array}{l}\text { All Siblings Live }>10 \mathrm{~km} \\
\text { of Father }\end{array}$ & & $0.65^{*}$ & 0.62 \\
\hline \multicolumn{4}{|l|}{ Proximity to In-Laws 2} \\
\hline \multicolumn{4}{|l|}{ No In-Laws (Reference) } \\
\hline $\begin{array}{l}\text { Live with/within } 10 \mathrm{~km} \\
\text { of } \geq 1 \text { In-Law }\end{array}$ & & -0.57 & -0.41 \\
\hline$>10 \mathrm{~km}$ from In-Laws & & $0.34^{*}$ & 0.42 \\
\hline \multicolumn{4}{|l|}{ Controls } \\
\hline Age $_{1}$ & & -0.01 & -0.00 \\
\hline Female & & 0.01 & -0.07 \\
\hline Employed/Enrolled $_{2}$ & & -0.03 & -0.03 \\
\hline Father Education $_{1}$ & & 0.02 & 0.01 \\
\hline Constant & $2.35^{* * *}$ & 0.51 & 0.37 \\
\hline Average $R^{2}$ & 0.01 & 0.22 & 0.24 \\
\hline
\end{tabular}

Note: Subscript denotes time.

* $p<.05$.

${ }^{* *} p<.01$.

*** $p<.001$

\section{Discussion and conclusion}

Using the Netherlands Kinship Panel Study, this study explored the spatial distance of adult children from their parents, paying particular attention to the role that early intergenerational cohesion plays in later residential choice. The role of early independence from the parental household in the cohesion-proximity relationship was also considered.

Residential location and choice have been studied from a variety of micro and macrotheoretical perspectives and several different methodological approaches. At the same time, little to no attention has been given to early-life factors (particularly family solidarity) as motivational factors for later residential location choices. Understanding the 
dynamics of parent-child proximity has many important theoretical and practical implications-namely, contact with parents (by way of spatial proximity to them) is a main facilitator in the transmission of care and support in family networks (Bian et al., 1998; Stuifbergen, van Delden, \& Dykstra, 2008).

Although no one would doubt the importance of proximity to resource exchanges, to the extent that low intergenerational cohesion translates to greater residential distance, the relationship between proximity and exchange is overstated. Because research has not examined the association of the parent-child relationship with spatial proximity to parents in young adulthood, these analyses help clarify the role that selection based on early parent-child relationship quality plays in the established proximity-contact relationship.

Overall, consistent with the hypothesis that early intergenerational cohesion is negatively associated with later spatial distance to parents, the results of this study suggest that individuals with close emotional relationships to their parents live closer to them later. All things considered, as expected, parent-child cohesion is a strong and significant predictor of later proximity to parents, even when controlling for other variables. In fact, other measures of intergenerational solidarity (e.g., parent marital quality and parent-child conflict at Wave 2) are less important than the parent-child bond itself. These findings highlight the importance of early intergenerational solidarity on later distance to mothers and fathers. All in all, the hypothesis that emotional closeness to a parent is negatively associated with later spatial distance is substantiated. Considering the pervasiveness of labor market explanations for long-distance migration, these results suggest that high-quality relationships with parents could act as a barrier to long-distance migration for career opportunities and advancement.

Early independence from the parental household is an important predictor of later geographic distance to parents. Michielin and Mulder (2007) found that individuals who leave home at early ages have more time to make distance moves. There is support for this second hypothesis, based on the idea that early independence from the parental household is positively associated with T2 distance. This association is apparently not just a matter of children abandoning unhappy relationships earlier, because the association of distance and the timing of nestleaving holds when cohesion is controlled. Still, early emotional closeness to parent operates independently of early nest-leaving in its significant association with spatial distance to parent. Thus, there is a significant relationship between early nest-leaving and greater distance to parents.

Through analysis of a large, longitudinal, geographically representative data set for the Netherlands, the current research offers an extension of previous research on parent-child cohesion, intergenerational exchanges, and spatial proximity to parents. The main aim of this study was to examine the relationship between emotional closeness to parents at age 15 (measured retrospectively at Wave 1) and T2 proximity. For both mothers and fathers, each set of models yielded qualified evidence of this relationship. This finding highlights a potential selection issue related to intergenerational support and contact as it is facilitated by geographic proximity. Specifically, individuals who live closer to their parents may have warmer and more enduring relationships with them.

This study has several limitations that should be addressed in future research. One limitation is that children who are emotionally close (or not close) to their parents may differ along a number of unobserved characteristics that are related to residential choice and distance. As noted, a more robust test of Hypothesis 1 would include an additional control for parent-child spatial proximity at Wave 1 . However, given that many respondents did not relocate between Waves 1 and 2, there was not enough statistical power for its inclusion in the final regression models. Nevertheless, the extensive set of theoretically relevant control variables in this study provides some reassurance that the relationship between early intergenerational cohesion and later distance to parents is a robust one.

Another limitation, common in retrospective studies, is that of recall-children may not be able to recall accurately their relationship with their parents at age 15 . Using a recall measure for parent-child closeness at age 15 poses potential measurement issues. For example, such retrospective measures run the risk of "telescoping," where individuals' memory of the adolescent-parent relationship may be biased by the current parent-child relationship (Bradburn, Huttenlocher, \& Hedges, 1993). To the extent that this is a major issue, reverse causality might go unnoticed in the hypothesized cohesion-proximity relationship. However, using a scale based on multiple items may have helped account for some of the nuance and complexity of the early parent-child relationship. Related, there tend to be differences in parent and child reports on their relationship. In particular, parents tend to report somewhat more positively than children (Giarrusso, Stallings, \& Bengtson, 1995). However, this problem is attenuated by the fact that children (i.e., the ones reporting intergenerational closeness) are the ones using this affective solidarity to influence their decision to move, and where.

As with most panel data sets, the NKPS has its own limitations. Although longitudinal data provide insights that cannot be gleaned from cross-sectional data, panel studies have particular vulnerability to attrition-this may pose a problem if the individuals who drop out of the study differ from the rest of the sample (e.g., those migrating out of the Netherlands). Another limitation of the NKPS is that only two waves are publicly available at this time. This is problematic because we are unable to examine individuals who relocate across a distance but return to the parental home (i.e., "boomerang") later in life. Lastly, the NKPS only interviews respondents age 18 and over. To attain more certainty about the relationship between intergenerational cohesion and later spatial proximity to parents, other data might permit future research to consider younger ages to examine the relationship between adolescent emotional closeness to parents and later-life spatial proximity to them. 
All in all, these findings paint a more complete picture of spatial proximity and residential choice. Although proximity is one of the strongest predictors of intergenerational exchanges (Rossi \& Rossi, 1990; Treas \& Gubernskaya, 2012), prior work may have overestimated the role of spatial proximity by not considering the emotional closeness between adult children and their parents that may select them into living closer and exchanging more resources and support. After controlling for T2 parentchild conflict, the parental relationship, and an extensive host of push and pull factors, the cohesion/proximity relationship holds.

Troubled relationships between parents and children appear to be a larger threat to family dynamics than sheer quantity of support. In light of these results, awareness should be raised that maintaining meaningful parentadolescent relationships requires active commitment to promote solidarity, opportunity structure, and greater overall well-being. Future research might consider points of intervention at adolescence in order to preserve highquality relationships and prevent deterioration of emotional closeness between parents and adolescent children. Thus, the current findings suggest that practice, such as family counseling, may be important to promoting healthy relationships between parents and their adolescent offspring.

At a more conceptual level, these results suggest the need to move beyond just looking at the contribution of structural characteristics in predicting spatial distance to parents. It may be substantively worthwhile for future research to consider early-life factors, particularly relationship quality such as intergenerational cohesion, in the study of spatial distance. Although young adults may move for a variety of reasons, early intergenerational cohesion is an important predictor of later spatial distance.

\section{Acknowledgments}

The authors are thankful to the National Science Foundation (Grant \# OISE-1132812) for their generous support as well as Judith Treas, Anne Schwichtenberg, and the anonymous reviewers for their helpful advice and comments on early versions of this manuscript.

\section{References}

Allen, K. R., Blieszner, R., \& Roberto, K. A. (2000). Families in the middle and later years: A review and critique of research in the 1990. Journal of Marriage and the Family, 62, 911-926.

Allison, P. D. (2002). Missing data. Thousand Oaks, CA: Sage.

Bengtson, V. L., \& Roberts, R. E. L. (1991). Intergenerational solidarity in aging families: An example of formal theory construction. Journal of Marriage and the Family, 53(4), 856-870.

Bian, F., Logan, J. R., \& Bian, Y. (1998). Intergenerational relations in urban China: Proximity, contact, and help to parents. Demography, 35(1), 115 124.

Bodner, T. E. (2008). What improves with increased missing data imputations? Structural Equation Modeling, 15(4), 651-675.

Bradburn, N. M., Huttenlocher, J., \& Hedges, L. (1993). Telescoping and temporal memory. In N. Schwarz \& S. Sudman (Eds.), Autobiographical memory and the validity of retrospective reports (pp. 203-215). New York, NY: Springer-Verlag.

Cadwallader, M. (1992). Migration and residential mobility: Micro and macro approaches. Madison, WI: University of Wisconsin Press.
Cheal, D. J. (1983). Intergenerational family transfers. Journal of Marriage and the Family, 45(4), 805-813.

Ciairano, S., Kliewer, W., Bonino, S., \& Bosma, H. A. (2008). Parenting and adolescent well-being in two European countries. Adolescence, 43(169), 99-117.

Coleman, J. S. (1988). Social capital in the creation of human capital. American Journal of Sociology, 94(Suppl.), S95-S120.

Conger, R. D., Ge, X., Elder, G. H., Jr., Lorenz, F. O., \& Simons, R. L. (1994). Economic stress, coercive family process, and developmental problems of adolescents. Child Development, 65(2), 541-561.

DaVanzo, J. (1981). Repeat migration, information costs, and location-specific capital. Population and Environment, 4(1), 45-73.

DeWit, D. J., Wister, A. V., \& Burch, T. K. (1988). Physical distance and social contact between elders and their adult children. Research on Aging, 10(1), 56-80.

Dykstra, P. A., Kalmijn, M., Knijn, T. C. M., Komter, A. E., Liefbroer, A. C., \& Mulder, C. H. (2005). Codebook of the Netherlands Kinship Panel Study, a multi-actor, multi-method panel study on solidarity in family relationships, Wave 1. The Hague: Netherlands Interdisciplinary Demographic Institute.

Elder, G. H., Jr. (1987). War mobilization and the life course: A cohort of World War II veterans. Sociological Forum, 2(3), 449-472.

Elder, G. H., Jr. (1994). Time, human agency, and social change: Perspectives on the life course. Social Psychology Quarterly, 57(1), 4-15.

Elder, G. H., Jr. (1998). The life course as developmental theory. Child Development, 69(1), 1-12.

Farrell, M. P., \& Barnes, G. M. (1993). Family systems and social support: A test of the effects of cohesion and adaptability on the functioning of parents and adolescents. Journal of Marriage and the Family, 55(1), 119132.

Ganzeboom, H. B. G., Graaf, P. M. D., \& Treiman, D. J. (1992). A standard international socio-economic index of occupational status. Social Science Research, 21, 1-56.

Geist, C., \& McManus, P. A. (2008). Geographical mobility over the life course: Motivations and implications. Population, Space and Place, 14, 283-303.

Giarrusso, R., Stallings, M., \& Bengtson, V. L. (1995). The "intergenerational stake" hypothesis revisited: Parent-child differences in perceptions of relationships 20 years later. In V. L. Bengtson, K. W. Schaie, \& L. M. Burton (Eds.), Intergenerational issues in aging: Effects of societal change (pp. 227263). New York: Springer.

Glaser, K., Price, D., Montserrat, E. R., di Gessa, G., \& Tinker, A. (2013). Grandparenting in Europe: Family policy and grandparents' role in providing childcare. London: Grandparents Plus.

Godwin, D. D. (1985). Simultaneous equations methods in family research. Journal of Marriage and the Family, 47, 9-22.

Greenwell, L., \& Bengtson, V. L. (1997). Geographic distance and contact between middle-aged children and their parents: The effects of social class over 20 years. Journal of Gerontology, 52B(1), S13-S26.

Hair, E. C., Moore, K. A., Garrett, S. B., Ling, T., \& Cleveland, K. (2008). The continued importance of quality parent-adolescent relationships during late adolescence. Journal of Research on Adolescence, 18(1), 187-200.

Iacovou, M. (2010). Leaving home: Independence, togetherness, and income. Advances in Life Course Research, 15, 147-160.

Ingersoll-Dayton, B., Neal, M. B., Ha, J.-H., \& Hammer, L. B. (2003). Redressing inequity in parent care among siblings. Journal of Marriage and Family, 65(1), 201-212.

Kalmijn, M.(2006). Educational inequality and family relationships: Influences on contact and proximity. European Sociological Review, 22(1), 1-16.

Kalmijn, M., \& Bernasco, W. (2001). Joint and separated lifestyles in couple relationships. Journal of Marriage and Family, 63, 639-694.

Kalmijn, M., \& Graaf, P. M. D. (2012). Life course changes of children and well-being of parents. Journal of Marriage and Family, 74, 269-280.

Klein Ikkink, K., Tilburg, T. v., \& Knipscheer, K. C. P. M. (1999). Perceived instrumental support exchanges in relationships between elderly parents and their adult children: Normative and structural explanations. Journal of Marriage and the Family, 61(4), 831-844.

Knijn, T. C. M., \& Liefbroer, A. C. (2006). More than kind: Instrumental support in families. In P. A. Dykstra, M. Kalmijn, T. C. M. Knijn, A. E. Komter, A. C. Liefbroer, \& C. H. Mulder (Eds.), Family solidarity in the Netherlands (pp. 89-106). Amsterdam: Dutch University Press.

Konrad, K. A., Kunemund, H., Lommerud, K. E., \& Robledo, J. R. (2002). Geography of the family. American Economic Review, 92(4), 981-998.

Lee, G. R., Dwyer, J. W., \& Coward, R. T. (1990). Residential location and proximity to children among impaired elderly parents. Rural Sociology, 55(4), 579-589.

Leopold, T. (2012). The legacy of leaving home: Long-term effects of coresidence on parent-child relationships. Journal of Marriage and Family, 74(3), 399-412.

Liefbroer, A. C., \& Mulder, C. H. (2006). Family obligations. In P. A. Dykstra, M. Kalmijn, T. C. M. Knijn, A. E. Komter, A. C. Liefbroer, \& C. H. Mulder (Eds.), 
Family solidarity in the Netherlands (pp. 123-142). Amsterdam: Dutch University Press.

Lin, G., \& Rogerson, P. A. (1995). Elderly parents and the geographic availability of their adult children. Research on Aging, 17(3), 303-331.

Long, L. H. (1992). Changing residence: Comparative perspectives on its relationship to age, sex, and marital status. Population Studies, 46(1), 141-158.

Longley, P. A., Clarke, M., \& Williams, H. C. W. L. (1991). Housing careers, asset accumulation and subsidies to owner occupiers-A microsimulation. Housing Studies, 6, 57-69.

Massey, D. S. (1990). Social structure, household strategies, and the cumulative causation of migration. Population Index, 56(1), 3-26.

Merz, E., \& Jak, S. (2013). The long reach of childhood: Childhood experiences influence close relationships and loneliness across life. Advances in Life Course Research, 18(3), 212-222.

Michielin, F. \& Mulder, C. H. (2007). Geographical distances between adult children and their parents in the Netherlands. Demographic Research, 17(22), 655-678.

Mincer, J. (1978). Family migration decisions. Journal of Political Economy, 86(5), 749-773.

Mulder, C. H., Clark, W. A. V., \& Wagner, M. (2002). A comparative analysis of leaving home in the United States, the Netherlands, and West Germany. Demographic Research, 7(17), 565-592.

Mulder, C. H., \& Kalmijn, M. (2006). Geographical distances between family members. In P. A. Dykstra, M. Kalmijn, T. C. M. Knijn, A. E. Komter, A. C. Liefbroer, \& C. H. Mulder (Eds.), Family solidarity in the Netherlands (pp. 43-62). Amsterdam: Dutch University Press.

Palloni, A., Massey, D. S., Ceballos, M., Espinosa, K., \& Spittel, M. (2001). A test using information on family networks. American Journal of Sociology 106(5), 1262-1298.

Pyke, K. (1999). The micropolitics of care in relationships between aging parents and adult children: Individualism, collectivism, and power. Journal of Marriage and the Family, 61(3), 661-672.

Rainer, H., \& Siedler, T. (2012). Family location and caregiving patterns from an international perspective. Population and Development Review, 38(2), $337-351$

Rappaport, J. (2007). Moving to nice weather. Regional Science and Urban Economics, 37(3), 375-398.

Rogerson, P. A., Weng, R. H., \& Lin, G. (1993). The spatial separation of parents and their adult children. Annals of the Association of American Geographers, 83(4), 656-671.

Rosenthal, C. J. (1985). Kinkeeping in the familial division of labor. Journal of Marriage and the Family, 47(4), 965-974.
Rossi, A., \& Rossi, P. H. (1990). Of human bonding: Parent child relations across the life course. Chicago: Aldine Press.

Sandefur, G. D., \& Scott, W. J. (1981). A dynamic analysis of migration: An assessment of the effects of age, family and career variables. Demography, 18(3), 355-368.

Sarkisian, N., \& Gerstel, N. (2004). Explaining the gender gap in help to parents: The importance of employment. Journal of Marriage and Family, 66(2), 431-451.

Schenk, N., \& Dykstra, P. A. (2012). Continuity and change in intergenerational family relationships: An examination of shifts in relationship type over a three-year period. Advances in Life Course Research, 17(3) $121-132$.

Silverstein, M. (1995). Stability and change in temporal distance between the elderly and their children. Demography, 32(1), 29-45.

Silverstein, M., Conroy, S. J., Wang, H., Giarrusso, R., \& Bengtson, V. L. (2002). Reciprocity in parent-child relations over the adult life course. Journal of Gerontology, 57B(1), S3-S13.

Sjaastad, L. A. (1962). The costs and returns of human migration. Journal of Political Economy, 70(5), 80-93.

Sorkin, D. H., \& Rook, K. S. (2006). Dealing with negative social exchanges in later life: Coping responses, goals, and effectiveness. Psychology and Aging, 21(4), 715-725.

Spilimbergo, A., \& Ubeda, L. (2004). Family attachment and the decision to move by race. Journal of Urban Economics, 55(3), 478-497.

Steinbach, A. (2012). Intergenerational relations across the life course. Advances in Life Course Research, 17(3), 93-99.

Stuifbergen, M. C., van Elden, J. J. M., \& Dykstra, P. A. (2008). The implications of today's family structures for support giving to older parents. Ageing $\mathcal{E}$ Society, 28, 413-434

Swartz, T. T. (2009). Intergenerational family relations in adulthood: Patterns, variations, and implications in the contemporary United States. Annual Review of Sociology, 35, 191-212.

Treas, J., \& Gubernskaya, Z. (2012). Farewell to moms? Maternal contact for seven countries in 1986 and 2001. Journal of Marriage and Family, 74, 297-311.

U.S. Census Bureau (2012). Geographic mobility: March 2010 to March 2011. Current population reports. Washington, DC: US Government Printing Office.

van der Lippe, T., \& van Dijk, L. (2002). Comparative research on women's employment. Annual Review of Sociology, 28, 221-241.

Ward, R. A., \& Spitze, G. D. (2007). Nestleaving and coresidence by young adult children: The role of family relations. Research on Aging, 29(3), 257-277. 